\title{
Neurohormonal Control of Lactation and Milk Let-down in Dairy Animals
}

\author{
A. Bhimte ${ }^{1 *}$, N.S. Thakur ${ }^{1}$, V.P. Maurya ${ }^{2}$ and G. Singh ${ }^{2}$ \\ ${ }^{1}$ Division of Animal Physiology, National Dairy Research Institute, \\ Karnal-132001, Haryana, India \\ ${ }^{2}$ Division of Physiology and Climatology ICAR-Indian Veterinary Research Institute, \\ Izzatnagar-243122, U.P., India \\ *Corresponding author
}

\section{A B S T R A C T}

\begin{tabular}{|l|}
\hline K e y w o r d s \\
Lactation, Milk \\
ejection, \\
$\begin{array}{l}\text { Neuroendocrine } \\
\text { reflex, Intammary } \\
\text { pressure (IMM), } \\
\text { Hypothalamus }\end{array}$ \\
\hline Article Info \\
\hline $\begin{array}{l}\text { Accepted: } \\
\text { 08 June } 2018 \\
\text { Available Online: } \\
\text { 10 July 2018 }\end{array}$ \\
\hline
\end{tabular}

\section{Introduction}

Lactogenesis is the process of differentiation where by the mammary alveolar cell acquires ability to secrete the milk. Once initiated, secretion of milk by alveolar epithelial cells is a continuous process but secretion does not occur at a constant rate over time. Maintenance of secretion throughout an individual lactation cycle requires regular removal of milk from the gland (Alexandrova et al., 1980). Rate of milk secretion depends on available storage capacity within the gland. Rate of milk secretion is fastest immediately after milk removal via suckling or milking and slows dramatically by 10-12 hours. Implementing a shorter interval between subsequent bouts of milk removal can increase milk production capacity. Approximately 35 hours after the most recent milk removal, milk secretion essentially stops. Control of milk secretion is achieved through both physical and chemical interactions (Bisset et al., 1970).

\section{Physical interactions}

Physical limitations are achieved through the build- up of pressure within the alveoli, 
resulting in an inverse relationship between intramammary (IMM) pressure and milk secretion rate (Lincoln et al., 1981). As milk pressure builds up, supporting structures, such as blood vessels, will be displaced, which in turn will limit the delivery of nutrients to alveolar cells. Pressure within the gland is highest at milking or suckling time, when teat stimulation causes oxytocin release (Lincoln et al., 1974) and contraction of myoepithelial cells, resulting in milk letdown. During this time, IMM pressure is approximately $35-55$ $\mathrm{mmHg}$.

As the milk removal process continues, pressure will drop to near zero independently of the amount of milk removed. Within 1 hour of milking, pressure will increase to a level of approximately $8 \mathrm{mmHg}$ and continues to increase steadily until the next milking. In dairy cattle, high- and low- yielding cows experience the same change in absolute pressure but the pressure per unit of newly secreted milk is lower in high yielding cows.

\section{Chemical interactions}

Chemical control of milk secretion appears to occur at the local level through a protein fraction called feedback inhibitor of lactation (FIL), which is secreted by mammary epithelial cells. Milk secretion rate is inversely proportional to FIL concentration in the alveoli.

FIL's mode of action is not fully understood, but it apparently works to slow milk secretion rate by suppressing key enzymes in epithelial cells, thus slowing secretion of key milk components. Over time, increasing concentrations of FIL stimulate intracellular breakdown of casein, reduces the number of prolactin receptors on mammary epithelial cells, and inhibits differentiation of mammary epithelial cells.

\section{Control of lactogenesis}

Lactogenesis is two stage mechanisms:

1) The first stage of lactogenesis consists of partial enzymatic and cytological differentiation of the alveolar cells and coincides with limited milk secretion before parturition

2) The second stage begins with the copious secretion of the milk component shortly before parturition and extends throughout postpartum in most species.

The development of the rough endoplasmic reticulum, smooth endoplasmic reticulum and the Golgi apparatus results in mammary synthesis of protein fat and lactose respectively. Following exposure to lactogenic hormones, differentiation of the mammary secretory cell will occur. The presence of blood progesterone through late pregnancy significantly blocks lactogenesis. In late pregnancy, the corpus luteum regresses, and the mammary gland is then free to respond to the hormones of the lactogenic complex (insulin, glucocorticoides and prolactin). At mid pregnancy, mammary cells have little rough endoplasmic reticulum, Golgi apparatus, and casein protein. Stimulation of the mammary gland by multiple hormones is required for lactogenesis. Decreasing the degradation rate of mRNA from the milk protein. Prolactin act by increasing the transcription rate of mRNA from milk protein gene directly stimulates the transcription of casein genes and other protein genes. Prolactin which is the site of synthesis of casein proteins and some of the whey proteins that will be exported from the secretory wall (Tyson et al., 1972) induces the differentiation of the rough endoplasmic reticulum. Glucocorticoide hormones (cortisol) presence of insulin induces the sensitivity to other hormones. The presence of insulin is requires for protein production. Insulin up regulate several genes in the mammary gland. 


\section{Progesterone roles on lactogenic hormones}

The progesterone block on lactogenesis is not however absolute. If it were absolute, the simultaneous pregnancy and lactation would be impossible. Progesterone significantly reduces the synergism between estrogen and prolactin. Progesterone decreases the ability of prolactin to induce secretion of $\alpha$ lactalbumin, an enzyme moiety of lactose synthase. Progesterone inhibits prolactin induced stimulation of its own receptor and also inhibits many other action of prolactin, including transcription, stabilization and translation of mRNA for milk proteins. Withdrawal of progesterone triggers lactogenesis in the presence of Prolactin and glucocorticoides. Concurrent lactation and gestation have little effect on milk production and mammary cell numbers, but milk yield and mammary cell number decrease after the fifth month of concurrent gestation compared with non pregnant cows. In some species such as cattle and horse, consumption may occur during lactation. This loss of secretory cell lowers milk yield as lactation advances, the rate of decline of mammary cell loss exceeds the rate of cell division. After parturition, there is marked increase in milk yield in cows, which reaches a maximum in 2 to 8 weeks and the gradually decline.

\section{Galactopoiesis}

Thyroid hormone influences the Growth hormone, ACTH, Thyroid stimulating hormone, Insulin and Parathyroid hormone are required for the maintenance of lactation. Pituitary gland and its hormones are important integrators of the endocrine control of milk secretion (Lincoln et al., 1974). Hormonal control of galactopoiesis exogenous prolactin has a very little galactopoietics effect in lactating cows, but it causes a slight increase in milk yield of goats in late lactation (Bruhn et al., 1981). ACTH plays a direct role in lactation by exerting its effect on mammary cell numbers, their metabolic activity and milk synthesis as well as the intensity and duration of milk secretion. Administration of the parathyroid hormone stimulate milk yield and increases the concentration of plasma calcium level (Douglas et al., 1964). The increased milk yield may be maintained by the continuous use of exogenous somatotropin in lactating cows. Commercial exploitation of such an effect was not practical until the advent of the recombinant DNA technology that allowed the bovine growth hormone (bovine somatotropin) economically in laboratory. Its effects by effective partitioning of the available nutrients away from the body tissues and towards the milk synthesis. Growth hormone does not produce its effect by direct stimulation of mammary gland in ruminants. Growth hormone administration has a dose dependent effect on the stimulation of milk yield in dairy cows.

Feed intake and water consumption markedly affect the rate of milk secretion and both of these processes are regulated by hypothalamus. Stimulation of the mammary afferent nerve via the hypothalamus causes a variety of hormonal responses (Cross et al., 1974). There is no evidence that nerve supply directly affect the maintenance of secretory activity of the mammary alveolar epithelium. Conversely intense suckling of milk to adequate milk removal will not sustain lactation indefinitely. A hormonal complex control lactation, but unless milk is removed frequently from the mammary gland, synthesis of milk will not persist despite as adequate hormonal status.

\section{Role of suckling in milk secretion}

Milk ejection can be stimulated by suckling and milking, washing the udder, presence of the young. The mammary glands of mammals from the platypus (Renfree, 1979) to man are 
identical in fine structure, and consist of alveolar tissue within which milk is continuously secreted during lactation (Morris et al., 1978). An alveolar structure increases enormously (perhaps by 10000 -folds) the surface area for secretion relative to the external size of the gland, but at the same time complicates the problem of milk removal. Small ducts generate substantial surface tension forces that oppose the movement of fluids; suction is therefore a relatively ineffective method for removal of alveolar milk (Berde, 1968). The problem has been overcome by investing the alveoli in a basketlike reticulum of myoepithelium which contracts in response to oxytocin released from the posterior pituitary. When stimulated by oxytocin the alveoli are compressed and milk is expelled into the larger collecting ducts for removal by the sucking of the young (Tindal, 1978). Further, the establishment of a nervous link between the nipple and the oxytocinergic neurons of the hypothalamus allows milk ejection from the alveolar tissue to be co-ordinate with the sucking of the young (Tribollet et al., 1978). Thus is formed the most classical of neuroendocrine reflexes.
Our analysis of this reflex would, if we adopted a traditional approach, commence with the sensory input to the hypothalamus (afferent limb) and conclude with a study of the motor response, i.e. the release of oxytocin and milk ejection (efferent limb).

There is however sound reasons for reversing this procedure. The process of milk ejection is remarkably uniform in all mammals, but the same cannot be said of the afferent limb of the reflex arc. Alveoli contain $>80 \%$ of stored milk.

In the long term, the suckling process, elicits the release into the maternal blood of factors on which the maintenance of milk secretion (galactpoiesis) depends. Medium term (over a period of hours): In the medium term, removal of milk from the alveolar lumina prevents the local accumulation of chemical factors, which inhibit further secretion. Short term (over a period of hours): In the short term, sucklinginduced ejection allows the young to obtain almost all the milk present in the gland, although a small proportion (the residual milk) remains in the glands

Figure.1 Neurohormonal control of milk secretion (Senger, 2003)

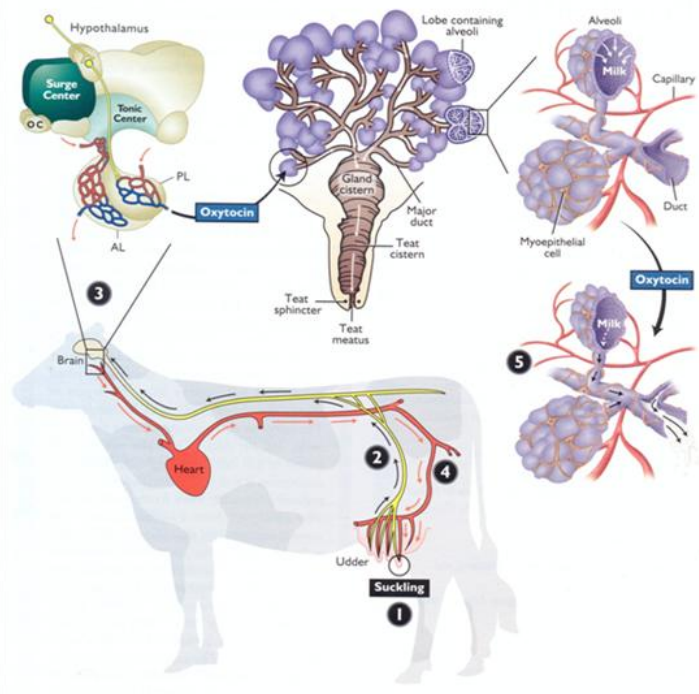




\section{Neurohormonal control of milk secretion}

This causes release of oxytocin and neurophysin into the blood (Dreifuss et al., 1971). The efferent pathway starts at this point. When the cell bodies of the oxytocincontaining neurons are stimulated by these impulses originating in the teat, an action potential moves down the oxytocincontaining neurons from the cell body in the hypothalamus down the axon to the neuron ending in the posterior pituitary. The nerve impulses travel to the brain through the spinothalamic nerve tract (Findlay, 1966). Mechanical stimulation of the teat activates pressure-sensitive nerve receptors in the skin of the teat.

The greatest amount of innervation in the mammary gland of the dairy cow is in the teats. Neural (afferent) component milk ejection reflex has a neural (afferent) and a hormonal (efferent) component. Epithelial secretory cells respond to very low levels of oxytocin. Injection of about 10 IU (international units) causes milk let down. However, as little as 0.02 IU can result in milk ejection. The number of oxytocin receptors increases to maximal during the first lactation, and persists for the lifetime of the secretory cell (Iversen et al., 1980). This results in contraction of the secretory cells and expulsion of milk from the mammary gland. It then travels to the mammary gland and binds to protein receptor sites on the epithelial secretory cells. Oxytocin is released into the blood in response to action potential of nerve impulses originated in the teat. The efferent pathway begins with the release of oxytocin into the blood.

\section{Hormonal (efferent) component}

The number of oxytocin receptors increases to maximal amount during the first lactation, then probably persists for the lifetime of the myoepithelial cell. This results in contraction of the myoepithelial cells and expulsion of milk from the mammary gland (Lincoln, Hill and Wakerley, 1973). An essential component of the milk ejection reflex is the binding of oxytocin, specifically and with high affinity, to protein receptor sites on the myoepithelial cells. Concentration then rapidly declines reaching a basal level within 10 minutes. Thus it is important to attach the milking machine to teat within 30-60 seconds of stimulating the teat. In cattle, the concentration of oxytocin in blood peaks within two minutes following the stimulation of teats. The timing of oxytocin release relative to milk removal is an important factor affecting milk ejection (Jessell et al., 1977).

\section{Milk ejection from the mammary gland}

Milk ejection is a neurohormonal reflex associated with the release of oxytocin. In some occasions, the intramammary pressure is sufficiently great to overcome the resistance of the teat sphincter so that the milk may leak from the teat. The flow of milk due to passive withdrawal, which is greatly increased following ejection, is commonly known as letdown. The ejection process results in a rapid transfer of milk from the lobulo-alveolar spaces into larger ducts. Ejection of milk is accomplished by contraction of the myoepithelial cells surrounding each alveolus. The contraction of the myoepithelial cell probably involves an oxytocin receptor-mediated depolarization of the cell membrane. During pregnancy the number of receptors in the mammary tissue of the rat increases progressively and remains relatively constant throughout lactation (Soloff et al., 1979). This contrasts markedly with the uterus where oxytocin receptors in the myometrium increase about 40 -fold in the hours immediately before parturition and rapidly disappear thereafter. These changes in receptor concentration in the uterus are 
related to dramatic changes in oestrogen, progesterone and prostaglandin production at the time of parturition (Alexandrova and Soloff, 1980; McCracken, 1980), though clearly the interaction is largely tissue specific and does not involve the mammary gland to any significant degree. One important consequence of these changes in receptor availability, when combined with the fact that copious milk production does not occur until shortly after parturition, is that oxytocin may be used sequentially, first to facilitate the delivery of the young and then later to promote milk ejection. The oxytocin receptors of the mammary gland are not notably specific. Vasopressin, the other major hormone of the posterior pituitary, has $25 \%$ of the milk-ejecting activity of oxytocin in the rat (Berde and Boissonnas, 1968).

\section{Inhibition of milk ejection}

Stressful stimuli will inhibit milk ejection

\section{Sympathetic nerves}

The neuro-endocrine components of sympathetic nerves are epinephrine and norepinephrine. Epinephrine (adrenaline) is primarily from adrenal medulla.

\section{Parasympathetic nerves}

There is no parasympathetic innervation in the mammary gland. The neurotransmitter of parasympathetic nerves is acetylcholine.

Epinephrine directly blocks oxytocin from binding to myoepithelial cells. This is termed peripheral inhibition of milk ejection. Thus, exogenous oxytocin will not cause milk ejection in animals exhibiting peripheral inhibition. This results in the reduction of oxytocin reaching the myoepithelial cells and partial occlusion of the mammary ducts (Lincoln and Renfree, 1981). The hormones are usually released in response to stressful situations and increase the tone of the smooth muscles of the mammary ducts and blood vessels. Oxytocin action can be blocked by catecholamines (epinephrine and norepinephrine). Various stressful stimuli that inhibit milk ejection are associated with increased activity of the sympathetic nervous system. Based on the above discussion about peripheral and central inhibition of milk ejection, it can be stated that milk ejection occurs as a result of oxytocin release, which is normally couples with inhibition of the central and peripheral inhibitory controls. Exogenous oxytocin is usually administered in these cases causing milk ejection. The stress inhibits the release of oxytocin from the posterior pituitary gland (central inhibition of milk ejection). A common cause of failure to milk ejection is associated with stress of milking in the early postpartum period especially for primiparous cows.

Norepinephrine reduces oxytocin release from the pituitary; this is an indirect effect mediated by inhibition of oxytocin release at the hypothalamic level (Lincoln et al., 1974). Norepinephrine decreases mammary blood flow (amount of oxytocin to the gland); this is an inhibition at the mammary tissue level (Jones and Pickering, 1972). Norepinephrine reduces myoepithelial cell contractile response to oxytocin; this is a direct inhibition at the myoepithelial cell level (Clarke et al., 1978).

In conclusion, lactation (milk removal) is essential for survival of new born. Lactation process is under the influence of neuroendocrine reflex. milk ejection induced by the release of oxytocin in response to suckling reflex, barn feeding, noise of milking matchine and mechanical stimulation to teat, these are the essential factors for the milk ejection in dairy cows. Milk removal can be disturbed at central or peripheral level under 
different conditions. The central disturbance represents a failure of ejection or insufficient ejection of the alveolar milk in to the cistern due to the inhibited oxytocin release from pituitary in to the blood circulation. For maintenance of dairy farm economic value high yielding dairy cows maintain in stress free environment.

\section{References}

Alexandrova, M. and Soloff, M.S. 1980. Oxytocin receptors and parturition. III. Increases in estrogen receptor and oxytocin receptor concentrations in the rat myometrium during prostaglandin F2a-induced abortion. Endocrinology. 106:739-743

Berde, B. and Bolssonnas, R.A. 1968. Basic pharmacological properties of synthetic analogues and homologues of the neurohypophysial hormones. Hand. Exp. Pharm. 23:802-870.

Bisset, G.W., Clark, BJ. and Haldar, J. 1970. Blood levels of oxytocin and vasopressin during suckling in the rabbit and the problem of their independent release. J. Physiol. Lond. 206: 711-722.

Clarke, G., Fall, C.H.D., Lincoln, D.W. and Merrick, L.P.1978. Effects of cholinoceptor antagonists on the suckling-induced and the experimentally evoked release of oxytocin. Br. J. Pharmac. 63: 519-527.

Cross, B.A. and Dyball, R.EJ. 1974. Central pathways for neurohypophysial hormone release. In Handbook of Physiology, Section 7, Vol. 4, the Pituitary Gland, Part 1, pp. 269-285. Eds E. Knobil and W. H. Sawyer. American Physiological Society, Washington, D.C.

Cross, B.A., Dyer, R.G., Dyball, R.E.J., Jones, C.A., Lincoln, D.W., Morris, J.F. and Pickering, B.T. 1975.
Endocrine neurons. Recent Prog. Horm. Res. 31: 243-292.

Douglas, W.W. and Poisner, A.M. 1964. Stimulus secretion coupling in a neurosecretory organ and the role of calcium in the release of vasopressin from the neurohypophysis. J. Physiol., Lond. 172, 1-18.

Dreifuss, J.J., Kalnins, I., Kelly, J.S. and Ruf, K.B. 1971. Action potentials and release of neurohypophysial hormones in vitro. J. Physiol., Lond. 215: 805817.

Findlay, A.L.R. 1966. Sensory discharges in lactating mammary glands. Nature, Lond. 211:1183-1184.

Dukes' Physiology of Domestic Animals, Thirteenth Edition, William O. Reece, University Professor Emeritus Department of Biomedical Sciences College of Veterinary Medicine Iowa State University, Ames, Iowa USA

Iversen, L.L., Iversen, S.D. and Bloom, F.E.1980. Opiate receptors influence vasopressin release from nerve terminals in rat neurohypophysis. Nature, Lond. 284: 350-351.

Jessell, T.M. and Iversen, L.L. 1977. Opiate analgesics inhibit substance release from rat trigeminal nucleus. Nature, Lond. 268: 549-551.

Jones, C.W. and Pickering, B.T. 1972. Intraaxonal transport and turnover of neurohypophysial hormones in the rat. I. Physiol., Lond. 227:553-564.

Lincoln, D.W. 1974a. Dynamics of oxytocin secretion. In Neurosecretion-the Final Neuroendocrine Pathway, pp. 192-194. Eds F. Knowles and L. Vollrath. Springer-Verlag, Heidelberg. Lincoln, D.W. and Renfree, M.B. 1981b. Mammary gland growth and milk ejection in the agile wallaby, Macropus agilis, displaying concurrent asynchronous lactation. J. Reprod. Fert. 63:193-203. 
Lincoln, D.W. and Wakerley, J.B. 1974. Electrophysiological evidence for the activation of supraoptic neurosecretory cells during the release of oxytocin. J. Physiol., Lond. 242: 533-554.

Lincoln, D.W. and Wakerley, J.B. 1975. Factors govern ing the periodic activation of supraoptic and paraventricular neurosecretory cells during suckling in the rat. /. Physiol., Lond. 250: 443-461.

Morris, J.F., Nordmann, JJ. and Dyball, R.EJ. 1978. Structure-function correlation in mammalian

neurosecretion. Int. rev. exp. Path. 18, 1-90. Pickering, B.T. The neurosecretory neurone: a model system for the study of secretion. Essays Biochem. 14:4581.

Poulain, D.A., Rodriguez, F. and Ellendorff, F. 1981. Sleep is not a prerequisite for milk ejection reflex in the pig. Expl Brain Res. 43: 107-110.
Renfree, M.B.1979. Initiation of development of diapausing embryo by mammary denervation lactation in a marsupial. Nature, Lond. 278: 549-551.

Senger, P.L. 2003. Pathways to pregnancy and parturition. 2nd edition. Current Conceptions, Inc. Pullman, WA.

Tindal, J.S. 1978. Central pathways in oxytocin and prolactin release. In Physiology and Mammary Glands, pp. 305-322. Eds A. Yokoyama, H. Mizuno and H. Nagasawa. University Park Press, Baltimore.

Tribollet, E., Clarke, G, Dreifuss, JJ. and Lincoln, D.W. 1978. The role of central adrenergic receptors in the reflex release of oxytocin. Brain Res. 142: 69-84

Tyson, J.E., Friesen, H. and Anderson, M. 1972. Human lactational and ovarian response to endogenous prolactin release. Science, N.Y. 177:897-900.

\section{How to cite this article:}

Bhimte, A., N.S. Thakur, V.P. Maurya and Singh, G. 2018. Neurohormonal Control of Lactation and Milk Let-down in Dairy Animals. Int.J.Curr.Microbiol.App.Sci. 7(07): 970-977. doi: https://doi.org/10.20546/ijcmas.2018.707.117 